\section{(C) \\ OPEN ACCESS}

\title{
Short stature and growth hormone deficiency: unexpected manifestations of McCune- Albright syndrome
}

\author{
Yordanka Pina Rivera, ${ }^{1,2}$ Godfrey Mutashambara Rwegerera, ${ }^{1,2}$ Sheikh Sesay ${ }^{3}$
}

'Department of Internal Medicine, University of Botswana, Gaborone, Botswana ${ }^{2}$ Department of Medicine, Princess Marina Hospital, Gaborone, Botswana ${ }^{3}$ Department of Radiology, Princess Marina Hospital, Gaborone, Botswana

Correspondence to Dr Godfrey

Mutashambara Rwegerera, grwege@yahoo.com

Accepted 28 July 2018

\section{SUMMARY}

McCune-Albright syndrome (MAS) is a rare disease characterised by triad of monostotic or polyostotic fibrous dysplasia, café au-lait skin spots and a variety of endocrine disorders; precocious puberty (PP) being the most common presenting symptom in female patients. Hyperfunction endocrinopathies including hyperthyroidism, growth hormone excess and cortisol excess are typical presentations in MAS. We present a case of 21-year-old woman with clinical and radiological characteristics of MAS triad; she presented with short stature which was attributed to both growth hormone deficiency and PP. Growth hormone deficiency in MAS has not been reported in English medical literature.

\section{BACKGROUND}

McCune-Albright syndrome (MAS) is a rare genetic disorder that was first described in 1936 by Dr Donovan McCune and Dr Fuller Albright. MAS affect 1 in 100000 to 1 in 1000000 people worldwide. It involves a triad of poly/monostotic fibrous dysplasia (FD), café-au-lait spots

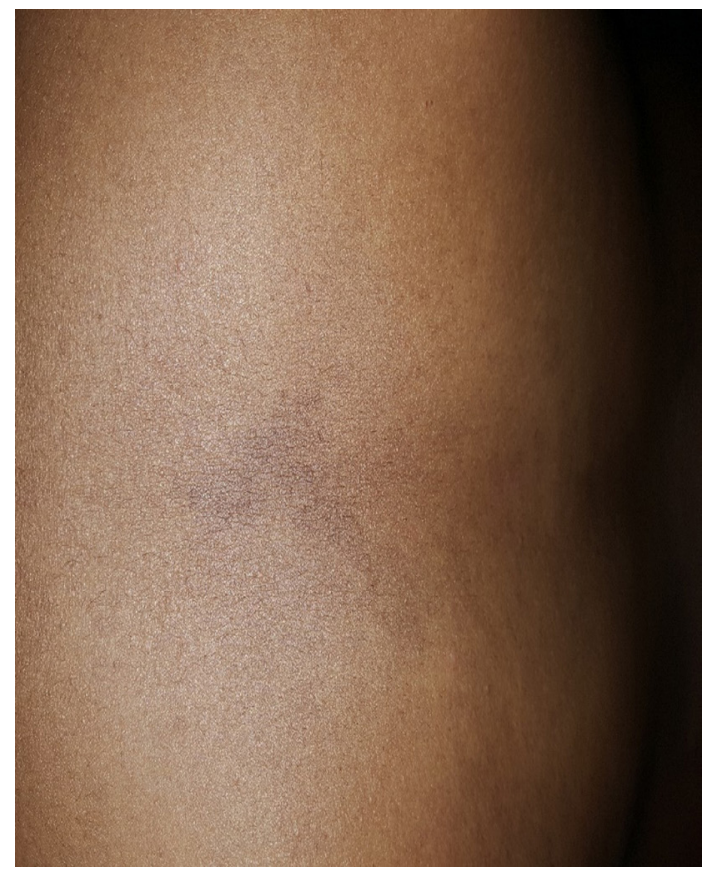

Figure 1 Café-au-lait spots in the middle line of the back. and endocrinopathies (predominantly involving precocious puberty in girls). ${ }^{1-5}$ Other common endocrinopathies involved in MAS include: hyperthyroidism, growth hormone $(\mathrm{GH})$ excess, hyperprolactenaemia, renal phosphate wasting, Cushing syndrome and ovarian cysts. ${ }^{2} 67$ Several other organ systems such as liver, heart, parathyroid and pancreas may occasionally be involved. ${ }^{8}$

MAS result from activating somatic mutations of the GNAS1 gene on the long arm of chromosome 20 ; specifically affecting Gs $\alpha$, a cAMP regulating protein. The mutation occurs during embryonic development and extent of disease and tissues involved are determined by the stage of embryonic development and survival of mutated cells. Activation of $\mathrm{Gs} \alpha$ is responsible for varied nature of endocrinopathies that occur in MAS. ${ }^{15-7}$ Gs $\alpha$ also acts as an 'on and off' switch protein to other body areas including skin (café au lait), ovary (precocious puberty) and bone (FD). ${ }^{1}$ Hypophosphataemia in MAS is explained by excess fibroblast growth factor 23 (FGF-23), a hormone produced by fibrous dysplastic bones and it causes the kidneys to lose phosphorus in the urine. ${ }^{1}$

Our index case is peculiar because at presentation and even during follow-up, there was persistence of $\mathrm{GH}$ deficiency.

\section{CASE PRESENTATION}

A 21-year-old woman presented at the endocrinology clinic complaining of short stature compared with her siblings and peers. She had a medical history of precocious puberty; her mother narrated that irregular menses started at the age of 3 years and only become regular when she was 9 years. Patients' breasts were also reported to develop since early childhood however galactorrhoea was not observed. There was no history of bone fractures. The rest of patient and social history was not significant. Physical examination revealed a young woman with short stature: height: $1.37 \mathrm{~m}$, weight: $37 \mathrm{~kg}$, temperature: $36.7^{\circ} \mathrm{C}$, pulse rate: 86 beats per minute, blood pressure: 115/68 $\mathrm{mm} \mathrm{Hg}$, café-aulait skin spots were found on the middle line of the back (figure 1) and lower abdomen. Both breasts were well developed (Tarner V), with adequate pubic hair distribution (Tarner IV), normal external female genitalia and normal clitoris. Visual fields and hearing were normal. 


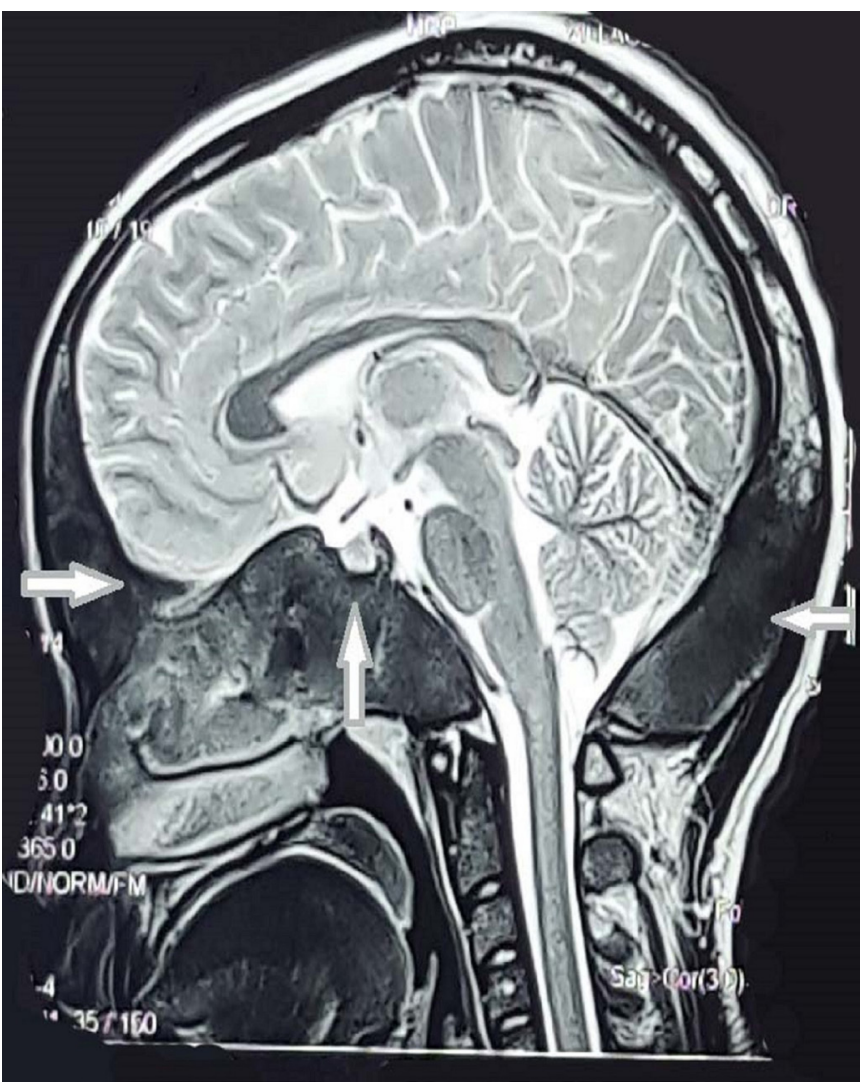

Figure 2 Brain MRI shows bone expansion and remodelling involving the frontal, parietal, occipital, sphenoid, clivus, right petrous-temporal, right zigoma and floor of sella turcica with fullness of sphenoid sinus.

\section{INVESTIGATIONS}

Routine laboratory tests and serum levels of luteinising hormone (LH), follicle-stimulating hormone (FSH), dehydroepiandrosterone sulfate (DHEAS), estradiol, prolactin, thyroid-stimulating hormone (TSH) and T4, adrenocorticotrophic hormone (ACTH) and basal cortisol were all within normal ranges. Unexpectedly serum insulin-like growth factor 1 (IGF-1) level was low (68 ng/ $\mathrm{mL}, \mathrm{N}$ : 267.5-470.8); subsequent clonidine test was done showing a GH deficiency with serum GH: $0.43 \mathrm{ng} / \mathrm{mL}, 0.29,0.13,0.09$ and 0.08 at $0,30,60,90$ and $120 \mathrm{~min}(<5 \mathrm{ng} / \mathrm{mL}$ indicative of $\mathrm{GH}$ deficiency). Abdominal-pelvic ultrasound revealed normal liver, gall bladder, kidneys, spleen and pancreas. Uterus, endometrium and left ovary appeared normal, whereas a follicular cyst measuring $2.7 \mathrm{~cm}$ in diameter was noted in the right ovary. Ultrasound of the neck ruled out thyroid and parathyroid glands enlargement. The brain MRI showed T1 hypointense signal lesions with bone expansion, remodelling and cranial asymmetry involving the frontal, parietal, occipital, sphenoid, clivus, right petrous-temporal and zygoma and floor of the sella turcica, with fullness of sphenoid sinus suggestive of FD (figure 2). FD was confirmed with a bone biopsy in histopathology department of hospital abroad. X-ray bone survey showed polyostotic FD involving skull, humeri, both femur and tibia (figure 3). Genetic testing was not available in our setting. The diagnosis of MAS was made based on clinical and radiological findings.

\section{TREATMENT}

The patient was treated with bisphosphonates in the form of ibandronate at a dosage of $150 \mathrm{mg}$ monthly to reduce the risk of pathological fractures for over the past 1 year of follow-up.

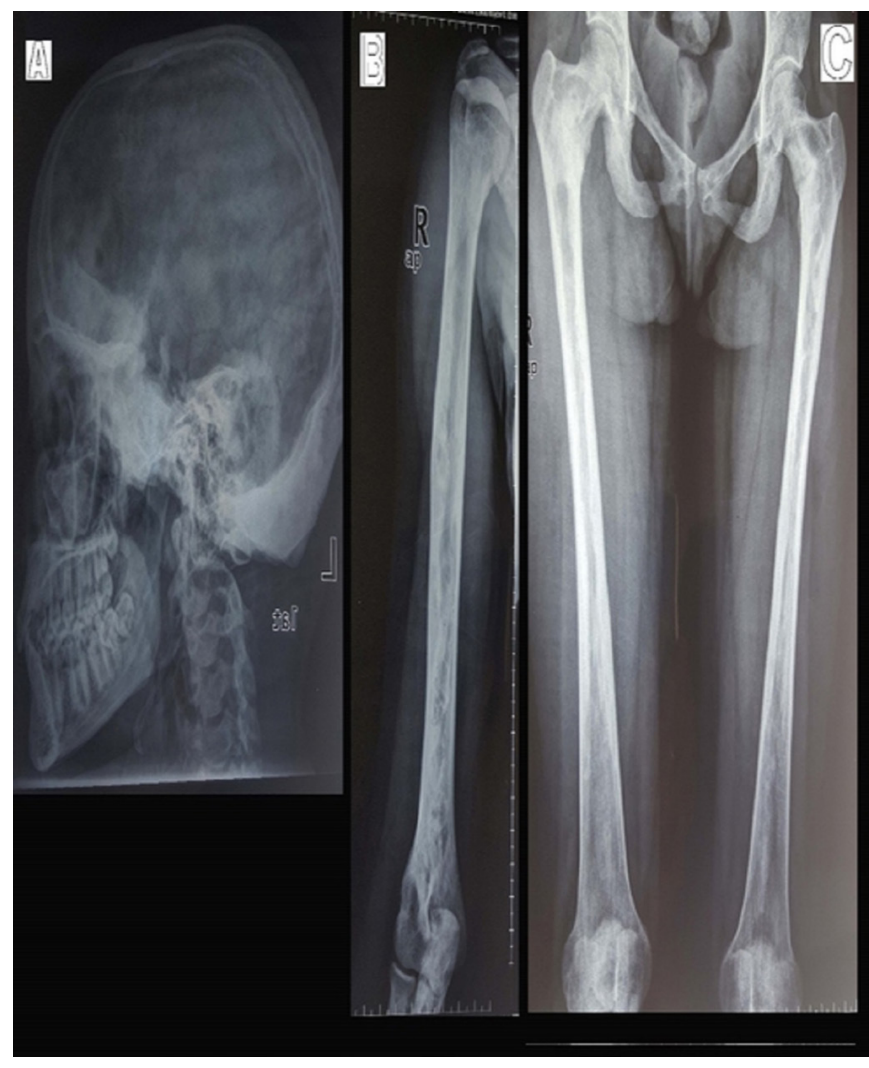

Figure 3 (A) Skull: sclerosis and expansion of the frontal bone and floor of the anterior cranial fossa extending into the sphenoid bone. Marked thickening and sclerosis of the occipital bone and posterior parietal bone. (B) Humerus: thickening of the cortex of the diaphysis, cystic lesions with thickened sclerotic rind in the methadiaphysis. (C) Femur: patchy sclerosis and expansion of the neck of both right and left femur, cortical thickening, scalloping and ground glass with radiolucency in the diaphysis bilaterally.

\section{OUTCOME AND FOLLOW-UP}

The patient has been followed up at endocrinology clinic for over the past 1 year. There is no change of clinical or laboratory sequela with recent hormone profile revealing persistence of $\mathrm{GH}$ deficiency $(\mathrm{IGF}-1=128 \mathrm{ng} / \mathrm{mL}$; GH at rest $=0.07 \mathrm{ug} / \mathrm{L}$ ). Other hormone profiles (LH, FSH, DHEAS, estradiol, prolactin, TSH and T4, ACTH and basal cortisol) have remained within the normal ranges. Haemogram, serum electrolytes, renal functions and liver enzymes are within the normal ranges except for raised alkaline phosphatase (ALP) $=154 \mu \mathrm{mol} / \mathrm{L}(35-110)$. Bone profile results were as follows: corrected serum calcium $=2.31 \mathrm{mmol} / \mathrm{L}$ (2.10-2.55); serum phosphate $=0.69 \mathrm{mmol} / \mathrm{L} \quad(0.87-1.47)$; 24-hour urine calcium and phosphate were $1.48 \mathrm{mmol}(0.8-$ $1.8)$ and $14.93 \mathrm{mmol} / \mathrm{L}(12.00-42.00)$, respectively; vitamin $\mathrm{D} 25-\mathrm{OH}=32.70 \mathrm{ng} / \mathrm{mL}$ ( $>20$ indicate sufficiency); $\mathrm{PTH}=60 \mathrm{pg} /$ $\mathrm{mL}(15.0-65.0)$. Tests for vitamin $\mathrm{D}(1,25(\mathrm{OH}) 2 \mathrm{D})$ and FGF-23 were not performed as they are not done both in the country and in Republic of South Africa.

\section{DISCUSSION}

MAS is always diagnosed on the basis of clinical background, supported by radiological findings of FD. Though the disease is caused by somatic mutation that occurs during embryonic stage, genetic testing is not necessary and there is no indication to screen other family members as the disease is not inherited. ${ }^{5}$ 
Short stature attributed to both GH deficiency and precocious puberty has not been reported in the triad of MAS; however, isolated cases of FD have reported the mechanism with which short stature may occur. Premature fusion of epiphysial growth plates secondary to defects in osteoblastic differentiation and maturation, hence resulting in short stature ${ }^{910}$; we speculate this is one possible mechanism of short stature in our patient as compared with her siblings and peers. On the other hand, GH deficiency found persistently in our patient could as well have contributed her phenotype. Oestrogen excess occurring early when patient had precocious puberty might also have accelerated bone maturation and short stature..$^{11}$ There was no documented follow-up of height for us to elicit this possibility.

Our patient presented with severe FD involving several bones in the scalp; we believe that GH deficiency most likely resulted from compression of pituitary region responsible for $\mathrm{GH}$ production by expanded dysplastic bones.

Despite the fact that our patient presented with widespread FD involving multiple bones; she did not present with bone pains and deformities; asymptomatic FD without bone pains or deformity has been described previously. ${ }^{12}$ Furthermore, diagnosis of FD in our patient was made through radiological findings after patient's clinical evaluation revealed the other two components of the triad. Findings on radiological images included sclerosis and expansion of several skull bones, cystic lesions and groundglass appearance with radiolucency; these are typical features as described by other authors. ${ }^{13}$

Hypophosphataemia in FD/MAS is usually caused by elevated levels of FGF-23. ${ }^{14}$ FGF-23 downregulates expression of sodium-phosphate cotransporters in the proximal tubule to stimulate phosphaturia resulting in hypophosphataemia. On the other hand, FGF-23 stimulates 24-hydroxylase to suppress the production of 1,25 dihydroxyvitamin $\mathrm{D}(1,25-(\mathrm{OH}) 2 \mathrm{D}) .{ }^{15} 16$ Normal PTH rules out a possibility of hyperparathyroidism-stimulating bone secretion of FGF-23. ${ }^{17}$

Analysis of the biochemical bone profile of our patient revealed mild hypophosphataemia and normal 24-hour urinary phosphate. Low dietary phosphate is one of the possibilities that can explain these findings. High dietary phosphate intake is known to cause high levels of FGF-23, while low dietary phosphate could cause the opposite resulting to hypophosphataemia and normal urine phosphate. ${ }^{18} 19$ Since we could not identify the phosphate content in the diet of our patient, our reasoning remain a speculation. Second explanation for not having elevated phosphate in urine is the fact that our patient had advanced bone disease which is associated with less bone activity, hence, less FGF- $23^{2021}$; this cannot be confirmed as this test is not available in our setting. On the other hand, postzygotic mutations of GNAS1 gene have been shown to account to lack of renal phosphate wasting in about $50 \%$ of patients with MAS/FD. ${ }^{22}$ Genetic testing was not performed in this case.

The rarity of MAS coupled with different manifestations of the condition depending on tissue involved makes choice of any specific treatment to be difficult; hence, management of the patient is based on controlling symptoms, strengthening exercises, stabilising the skeleton to prevent fractures and providing bisphosphonates which have been shown to help in reducing bone pains without necessarily altering natural history of the disease. ${ }^{73-25}$ Our patient has been receiving bisphosphonates in the form of ibandronate for over the past 1 year and she has not had any bone pains or fractures.

Despite persistence of GH deficiency, we did not prescribe GH analogues to our patient because the latter has been shown to make craniofacial FD worse. ${ }^{2627}$
Learning points

- McCune-Albright syndrome (MAS) presenting with a range of skeletal and extraskeletal manifestations requires extensive clinical, laboratory and radiological work up to enhance proper identification of extent of tissues involved.

- The case highlights the importance of appreciating the fact that hypofunction endocrinopathies manifestations may be a reason that patients seek medical attention.

- Short stature in MAS even in patients with a history of precocious puberty should alert physicians to seek for possible underlying growth hormone deficiency.

Acknowledgements The authors would also like to acknowledge the fact that the abstract for this case report was first submitted and accepted under the title 'McCune- Albright Syndrome with Growth Hormone Deficiency: Case report' and published (not presented) in conference proceedings of the 99th Annual Meeting of the Endocrine Society 2017 (1-4 April 2017). It is available online at: https://endo. confex.com/endo/2017endo/meetingapp.cgi/Paper/30124.

Contributors YPR and GMR: wrote the first draft of the manuscript; interpreted the clinical and laboratory findings. SS: interpreted the radiology images. All the authors read, corrected and approved the final manuscript.

Funding The authors have not declared a specific grant for this research from any funding agency in the public, commercial or not-for-profit sectors.

Competing interests None declared.

\section{Patient consent Obtained.}

Provenance and peer review Not commissioned; externally peer reviewed.

Open access This is an open access article distributed in accordance with the Creative Commons Attribution Non Commercial (CC BY-NC 4.0) license, which permits others to distribute, remix, adapt, build upon this work non-commercially, and license their derivative works on different terms, provided the original work is properly cited, appropriate credit is given, any changes made indicated, and the use is non-commercial. See: http://creativecommons.org/licenses/by-nc/4.0/.

\section{REFERENCES}

1 Guthrie L, Brillante B. Insights into McCune Albright syndrome: a complex, rare disease with individual presentations: PENS 2015 National Conference. (Last accessed 15 Apr2018).

2 McCune DJ. Osteitis fibrosa cystica: the case of a nine-year-old girl who also exhibits precocious puberty, multiple pigmentation of the skin and hyperthyroidism. Am J Dis Child 1936;52:743-4.

3 Albright F, Butler AM, Hampton AO, et al. Syndrome characterized by osteitis fibrosa disseminata, areas of pigmentation and endocrine dysfunction, with precocious puberty in females. N Engl J Med Overseas Ed 1937;216:727-46.

4 Tessaris D, Boyce AM, Zacharin M, et al. Growth hormone-Insulin-like growth factor 1 axis hyperactivity on bone fibrous dysplasia in McCune-Albright Syndrome. Clin Endocrinol 2018;89:56-64.

5 Robinson C, Collins MT, Boyce AM. Fibrous Dysplasia/McCune-Albright syndrome: clinical and translational perspectives. Curr Osteoporos Rep 2016;14:178-86.

6 Akintoye SO, Chebli C, Booher S, et al. Characterization of gsp-mediated growth hormone excess in the context of McCune-Albright syndrome. J Clin Endocrinol Metab 2002;87:5104-12.

7 Dumitrescu CE, Collins MT. McCune-Albright syndrome. Orphanet J Rare Dis 2008;19:3-12

8 Shenker A, Weinstein LS, Moran A, et al. Severe endocrine and nonendocrine manifestations of the McCune-Albright syndrome associated with activating mutations of stimulatory G protein GS. J Pediatr 1993;123:509-18.

9 Weerakkody Y, Singh G. Fibrous dysplasia. https://radiopaedia.org/articles/fibrousdysplasia (Last accessed 22 Apr 2018).

10 Cardino MJT, Tan CC, Jimeno C. Polyostotic fibrous dysplasia in a young female with mccune albright syndrome. Philippine Journal of Internal Medicine 2010;48:41-5.

11 Carel JC, Lahlou N, Roger M, et al. Precocious puberty and statural growth. Hum Reprod Update 2004;10:135-47.

12 Weinstein LS, Chen M, Liu J. Gs(alpha) mutations and imprinting defects in human disease. Ann N Y Acad Sci 2002;968:173-97.

13 Akintoye SO, Otis LL, Atkinson JC, et al. Analyses of variable panoramic radiographic characteristics of maxillo-mandibular fibrous dysplasia in McCune-Albright syndrome. Oral Dis 2004;10:36-43. 
14 Fukumoto S, Yamashita T. FGF23 is a hormone-regulating phosphate metabolism-unique biological characteristics of FGF23. Bone 2007;40:1190-5.

15 Shimada T, Urakawa I, Yamazaki Y, et al. FGF-23 transgenic mice demonstrate hypophosphatemic rickets with reduced expression of sodium phosphate cotransporter type Ila. Biochem Biophys Res Commun 2004;314:409-14.

16 Shimada T, Hasegawa H, Yamazaki Y, et al. FGF-23 is a potent regulator of vitamin D metabolism and phosphate homeostasis. J Bone Miner Res 2004;19:429-35.

17 Guo YC, Yuan Q. Fibroblast growth factor 23 and bone mineralisation. Int J Oral Sci $2015 ; 7: 8-13$.

18 Burnett SM, Gunawardene SC, Bringhurst FR, et al. Regulation of C-terminal and intact FGF-23 by dietary phosphate in men and women. J Bone Miner Res 2006:21:1187-96.

19 Antoniucci DM, Yamashita T, Portale AA. Dietary phosphorus regulates serum fibroblast growth factor-23 concentrations in healthy men. J Clin Endocrinol Metab 2006;91:3144-9.

20 Collins MT, Singer FR, Eugster E. McCune-Albright syndrome and the extraskeletal manifestations of fibrous dysplasia. Orphanet J Rare Dis 2012;7(Suppl 1):S4.

21 Kuznetsov SA, Cherman N, Riminucci M, et al. Age-dependent demise of GNASmutated skeletal stem cells and "normalization" of fibrous dysplasia of bone. J Bone Miner Res 2008;23:1731-40.
22 Riminucci M, Collins MT, Fedarko NS, et al. FGF-23 in fibrous dysplasia of bone and its relationship to renal phosphate wasting. J Clin Invest 2003;112:683-92.

23 Kumar N, Kheruka SC, Singh RK, et al. Hypothyroidism in McCune-Albright syndrome and role of bone scan in management of fibrous dysplasia: an unusual case scenario with review of literature. Indian J Nucl Med 2017;32:25-9.

24 Rodriguez ED, Bluebond-Langner R, Brazio P, et al. Near-total mandible reconstruction with a single fibula flap containing fibrous dysplasia in McCune Albright Syndrome. J Craniofac Surg 2007;18:1479-82.

25 Majoor BC, Appelman-Dijkstra NM, Fiocco M, et al. Outcome of long-term bisphosphonate therapy in mccune-albright syndrome and polyostotic fibrous dysplasia. J Bone Miner Res 2017;32:264-76.

26 Vasilev V, Daly AF, Thiry A, et al. McCune-Albright syndrome: a detailed pathological and genetic analysis of disease effects in an adult patient. J Clin Endocrinol Metab 2014;99:E2029-38.

27 Kano A, Mogi K, Negishi A, et al. Fibrous dysplasia-like jaw enlargement following treatment with growth hormone. Asian Journal of Oral and Maxillofacial Surgery 2006;18:62-6.

Copyright 2018 BMJ Publishing Group. All rights reserved. For permission to reuse any of this content visit http://group.bmj.com/group/rights-licensing/permissions.

BMJ Case Report Fellows may re-use this article for personal use and teaching without any further permission.

Become a Fellow of BMJ Case Reports today and you can:

- Submit as many cases as you like

- Enjoy fast sympathetic peer review and rapid publication of accepted articles

- Access all the published articles

- Re-use any of the published material for personal use and teaching without further permission

For information on Institutional Fellowships contact consortiasales@bmjgroup.com

Visit casereports.bmj.com for more articles like this and to become a Fellow 